\title{
A Survey Based Study Of Civil Engineering Education In Turkey
}

Gülçağ Albayrak

Department of Civil

Engineering, Eskişehir

Osmangazi University, Turkey

galbayrak@ogu.edu.tr
DOI 10.5592/otmcj.2014.2.2

Research paper

\section{Keywords}

Civil engineering education, Student survey, Problems in education

\author{
İlker Özdemir \\ Department of Civil \\ Engineering, Eskişehir \\ Osmangazi University, Turkey \\ iozdemir@ogu.edu.tr
}

\author{
Uğur Albayrak \\ Department of Civil \\ Engineering, Eskişehir \\ Osmangazi University, Turkey \\ albayrak@ogu.edu.tr
}

THE MAIN PURPOSE OF THE STUDY IS THE INVESTIGATION OF TEACHING QUALITIES OF SOME CIVIL ENGINEERING DEPARTMENTS IN TURKEY ASSESSMENT BY CIVIL ENGINEERING STUDENTS THAT ARE THE MAIN PART OF THIS TEACHING. Also, some solution proposals are offered to improve the quality of the teaching. In this context, students' opinions about the universities; development level of the faculty and the department; quality of courses and summer practices taken throughout their education and teaching programs; academic and scientific capabilities of faculty members and departments; the city and mass transportation opportunities are investigated.

The research is a questionnaire-based study and applied on total 301 undergraduate students from 6 different civil engineering departments which are categorized as developed, developing and newly established according to some criteria like as the foundation date of department, number of faculty members etc. Research data is evaluated by IBM SPSS Statistics V.20.0 that is a computer program generally used for survey authoring, data mining and statistical analysis. In this study, a reliable and valid scale is created to specify the current levels of educational environment by defining of students' value criteria that are expected from higher education institutions in learning process. 


\section{INTRODUCTION}

Universities are high-level academic and research institutions that their missions are training the persons who have scientific and academicals knowledge and power of free thought and expression. Likewise the engineers who grow in these institutions expected outstanding skills. Therefore the aim of engineering education is to give modern science, and engineering knowledge to students and therewithal creativity, research techniques and methods of solving problem. During engineering education, it is important to cultivate their ability to discover, analyze, and solve the problems to grow outstanding new engineers.

Civil engineering is the oldest engineering discipline when peoples started to give up a mobile existence, producing a need for the construction of shelter. Civil engineering is an engineering branch that aspect of life since the beginnings of human existence and has many working areas about the base of modern civilization infrastructure. The project and construction of buildings, hospitals, communication and industrial plants etc.; highways, roads, subway, railway and any transportation systems; ports, water supply and sewage systems so all structures are built by civil engineers. The researches about providing quality in engineering education are accelerated in Turkey also whole world especially for well educated civil engineers by considering the effects on social life. MUDEK (Association for Evaluation and Accreditation of Engineering Programs) which is a independent and private organization serving for the goal of contributing to the improvement of quality of engineering education and teaching in Turkey. This function is done by means of the accreditation and assessment and getting information services for different engineering education programs. MUDEK is founded in 2002 and full member of ENAEE (European Network for Accreditation of Engineering Education) since 2006.
According to MUDEK, these main areas must be involved in civil engineering programs presented below:

Mathematic including differential equations,

Probability and statistics,

- Calculus-based physics,

- Qualification on general chemistry,

> Qualification on at least four of the agreed main areas of civil engineering,

- Experiment laboratory tests and analyze, interpret data on at least two of the agreed

> Business-making, negotiation or quality-based selection processes in the tender procedure,

$\checkmark$ How to interact with designers and builders to complete a project,

$>$ Information about the issues of professional practice such as importance of adequacy and continuing education.

- Design ability in civil engineering lecture program by acquired information from design experience on vocational training [3].

Inadequacies of ordinary engineering education conditions are mentioned today in many national or international meetings. ASCE (American Society of Civil Engineering) also works on the education of civil engineering students. Knowledge and skills of future civil engineers for leadership among all engineering disciplines were argued on a conference named "The vision for civil engineering in 2025 " organized in 2006 [4]. In this conference, the main properties of future civil engineers to create a sustainable world and improve global life conditions are below:

- A master planner, builder and manager of the structural environment which is the main element of economic and social life,

- Protector of environmental and natural resources,

- Pioneer, and integrator of ideas and technologies in the public, private sector and academic areas,

Administrator of risks and uncertainties caused by natural disaster, accidents and any other threats,

Leaders of the debates and decisions about environmental and structural policies.

\section{Investigation of civil engineering education in Turkey}

It is argued that engineering education today is how contemporary and qualified because of rapid development in technology and continuously increment, form and dimension changes in the problems of universities. In this case, near-future problems and solution suggestions in civil engineering education must be questioned with an extensive scope.

\section{Literature}

There are many studies in literature about the state of civil engineering education in Turkey. In these studies; physical conditions and lecturers, laboratory and internship facilities, distribution and content of courses in civil engineering education are examined. On the other hand, problems and inadequacies in civil engineering departments compared to developed countries and employment after graduation. According to a common conclusion reached by the studies; changes in evaluation appraisals and lifestyles, incorrect approaches to education starting from primary school, perspectives of politicians to education, examinations like as a distorted race, and incompatibility of universities with the changing conditions are the major problems. For this reasons, solution of the problems given above is not only from the universities also the government point of view. The measures and changes taken from the universities will be useful for solving problems.

In 2008, According to a survey conducted by Chamber of Civil Engineers (IMO) which is a sub-organization of 
Union of Chambers of Turkish Engineers and Architects (TMMOB), a report is published in the name of "Reality of Civil Engineering Education in Turkey". In this report, the rate of preferring of civil engineering departments in matriculation is the between the first 3 choice is $57 \%$, the after the first 5 choice is $27 \%$. These ratios seems to be a good at first glance but considering matriculation in Turkey, preferring after the first 5 choice is made because of fear about non-entering any program in university so $27 \%$ of civil engineering students do not want to study in civil engineering departments actually.

\section{Purpose and method of the study}

The main purpose of the study is the investigation of teaching qualities of some civil engineering departments in Turkey assessment by civil engineering students that are the main part of this teaching and offer solution proposals to improve the quality of the teaching using value engineering principles under this as. Evaluation of civil engineering education from the students' point of view in Turkey is lacking in the literature so this investigation and study was performed in this direction. Data in the study was collected using survey with typical five-level Likert-type scale which is the most widely used approach to scaling responses in survey research. The format of the five-level Likert scale used in this study is given below:

1. Very Poor

2. Below Average

3. Average

4. Above Average

5. Excellent

In the survey, students' opinions about the universities they study and wish to study; development level of the faculty and the department; quality of courses and summer practices taken throughout their education and teaching programs; academic and scientific capabilities of faculty members and departments; the city where the university is and mass transportation opportunities

\begin{tabular}{|l|c|}
\hline University level & Number of students \\
\hline Developed & 94 \\
\hline Developing & 98 \\
\hline Newly established & 109 \\
\hline TOTAL & 301 \\
\hline
\end{tabular}

Table 1. The distribution of participants according to university level

for going to university are investigated by 20 different survey question.

Due to some restrictions such as time, cost and transport, research scope is restricted on total 301 undergraduate students from 6 different civil engineering departments which are categorized as developed, developing and newly established according to some criteria like as the foundation date of department, number of faculty members etc. Although the development level of universities can not be simply expressed in numbers; according to Saka and Yaman, development level of a university depends on number of publications in the reports prepared by The Turkey Council of Higher Education (YOK) which is responsible for the planning, coordination, governance and supervision of higher education in Turkey [5]. The survey was applied on total 301 undergraduate students from 6 different civil engineering departments that
94 students from developed universities, 98 students from developing and 109 students from newly established can be shown in Table 1 and Figure 1.

To interpret the survey data properly, take advantage of statistics and make an accurate analyzes. Various statistical analyse techniques are used to examine intergroup differences and relations, assumptions and interpretation of results. In this study, research data is evaluated by IBM SPSS Statistics v.20.0 that is a computer program used for survey authoring, data mining, statistical analysis, collaboration and deployment by the last edition as of the date of this study.

Furthermore reliability analysis and factor analysis were also performed regardless of the data are parametric or not. The level of statistical significance was $5 \%$ for all tests in this study,

Cronbach's alpha is a coefficient that commonly used as a measure of
The percentage of participants according to university level

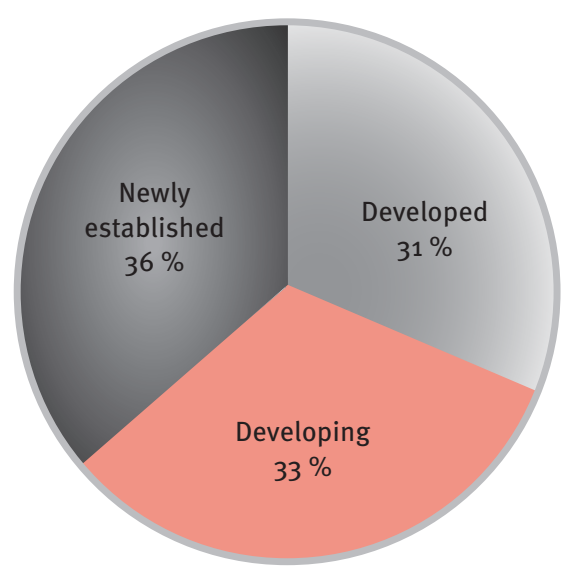

Figure 1. The percentage of participants according to university level 
the internal consistency or reliability in a statistical analysis so multiple Likert questions in a survey are available that form a scale and to determine if the scale is reliable. Cronbach's alpha is a function of the number of survey data and the average inter-correlation among the data. Cronbach's alpha simply provides with an overall reliability coefficient for a set of variables, e.g. questions. If the questions reflect different underlying personal dimensions then Cronbach's alpha will not be able to discern between these. By the way Cronbach's alpha coefficient is not sufficient alone for reliability analysis of a survey. After the operations doing by IBM SPSS, Cronbach's alpha coefficient is determined 0,806 so it can be said that the survey is reliable. Contribution of each question to the survey reliability is evaluated and as a result, Question 20 reduces the Cronbach's alpha coefficient and survey reliability so this question put out from the survey.

\section{Analysis of survey data}

Today engineering education is wanted to be more effective by using quality criteria on the other hand new universities and engineering faculties established and student quota is increased in engineering departments in Turkey. Engineering education is to be considered with students and academicians so increasing in student quota have to be proportional to lecturer number. In Turkey, there are some differences between the civil engineering departments in terms of number of lecturers, laboratories, classrooms and computer facilities etc.

In this study, it is observed that educational and research activities with current academic staff are not sufficient in terms of student satisfaction. In upcountry of Turkey, there is not enough teaching staff in civil engineering departments because of many departments were founded without exhaustive planning in these regions. For this reason, first of all quality of existing civil engineering departments have to be improved instead of foundation of new engineering departments. Some measures should be taken to ensure education quality. Being faculty member should be made more attractive, some programs should be developed to train lecturers and buildings and classrooms, laboratories, library etc units have to be provided. It should not be allowed to establish new departments unless these conditions are provided. The student quota should be reduced when the budgets of civil engineering departments are increased.

Since increase of student number in civil engineering departments because of quota increment, taking the course again or student amnesty; make difficult for watching the courses and making exams. Lecturers work under difficult conditions such as low-wage, teaching at crowded classrooms, lack of time and resources etc. therefore the academicians can not enough research. Engineering knowledge develop rapidly day by day so the academicians have to renew yourself to transfer new information to the students and make scientific researches and ensure advancement in academic ranks. The survey results also showed that the students even in developed universities indicate mid-level in terms of the number of annual publications of the department. The students answer the questions as poor/ inadequate for the survey results in developing and newly established departments.

In addition to theoretical knowledge, applications of the theories in engineering are very important. Summer and interim internships which are the system of on the job training to gain experience in civil engineering contribute engineering education and engineering life. In the study, the level of internships in developed and developing universities seems to be sufficient but in newly established universities indicated as mid-level. For more efficient internship, this process has to strict rules controlled by a committee to build a uniform internship program, monitor its effectiveness, and evaluation. In a civil engineering site, analytical abilities are not enough so the students must have both interpersonal and leadership skills.

In higher education, many new civil engineering departments founded with insufficient physical conditions so it can be easily said that "quantity rather than quality" whereas base of the engineering constituted by science and technology. Libraries equipped with national and international publications give research desires to the students and studies will always be open to innovation [6]. In this context, opinions from the students about education materials has been received so the state of education materials in developed universities is too much enough and in developing universities is very poor but in newly established universities indicated as mid-level. The number of research and text books in university libraries should be increased. Comfortable working environments in libraries should be prepared for students studies and access to information, internet, and photocopiers should be spread.

Especially in the last year of civil engineering education, using of fundamental and engineering sciences that students have should be teach to the students how to benefit from future. Otherwise students need somebody for teaching themselves about new issues meet in their professional lives [7]. According to the question which is about interpretation ability about the knowledge taught in lessons, there is a lack of this subject for 3 kinds of universities. The reason for this is existence of a system which based only give information and memorization. In order to giving interpretation ability to the students, course programs should be renewed as to advanced technology and requirements and should be dynamic and interactive. 
How the students think about adequate numbers of current course in the survey. According to developed university students the course contents are up to date moderately on the other hand in developing and newly established universities the course contents are very poor in terms of updating. Civil engineering education in Turkey does not have equivalent quality between all Turkish universities and advanced countries therefore course contents should be upgraded consistently.

According to survey data, point of view of the community to the department will be negative for developing and newly established universities but for developed universities just the opposite. Students from developed universities defined their universities as "highly respected" then from developing universities as "medium respected" and from newly established universities as "slightly respected". From this evaluation can be said that people show respect to old and developed universities or may be civil engineering is not respectable job for all regions. To increase the social prestige of civil engineers, first of all the definition of civil engineering should be arranged by a knowledge-base. Civil engineers are not the persons who construct buildings only. Civil engineering departments and chambers of civil engineers have to be more effective to assure this. Civil engineering may be choosing in the first 5 preferences with realistic presentations to high school students instead of first 10 preferences [8].

Only 10 years ago, the students who want to study in civil engineering departments were chosen from among the more successful students today in Turkey and also U.S.A. These students had learning capacity and ability to get more knowledge even though using ineffective teaching methods [9]. After the 2000s, the students that prefer civil engineering have chosen among less capable students, these students may have high potential but they must make up for the deficiencies from elementary and secondary education. Today's students are accustomed to receive information for a short time; there is no patience to get the information from books and long courses. For this reason, giving engineering education to these students using conventional methods is not efficient, but some lecturers are missing past years students and waiting for students change rather than system change instead of seeing the facts [10].

\section{Results}

There are many problems in all levels of higher education system in Turkey and it known and have been expressed by everyone. Points of attention for the issue of civil engineering education is tried to express in this work. In this study, a reliable and valid scale is created to specify the current levels of educational environment by defining of students' value criteria that are expected from higher education institutions in learning process. The data and results obtained with a limited survey do not exactly reflect the current state of education but there are considerable similarities. In general, the following conclusions are presented after the evaluation of the survey data.

According to the survey, preference degree of civil engineering departments of the students from developed universities is 4.1 (average value) where the highest score is 5.0 and it means that "above average" according to interpretation and evaluation scale of the survey. Development level of the department or faculty for developed universities is average 3.9 that means "average". Internship and course content level of these universities is average 3.2 that means "medium". Although the students study at the country's leading higher education institutions, give 3.4 that mean "average". The students from developed universities (in 2 metropolitan cities) give 3.7 for transportation and city.
According to the participants from developing universities, preference degree of civil engineering departments is 3.7 that means roughly “above average". Development level of the department or faculty for developing universities is average 2.9 that mean "medium", similarly internship and course content level of these universities is average 2.9 that mean "medium". Scientific capacity of the department from students' point of view for developing universities is $\mathbf{2 . 2}$ that mean "below average" and the students give 2.9 for transportation and city that mean "average".

Preference degree of civil engineering departments of the students from newly established universities is $\mathbf{3 . 2}$ and it means that "average". According to the participants from newly established universities, development level of the department or faculty is $\mathbf{2 . 5}$ and this number is close to developing universities but very different from developed university score. Internship and course content level of these universities is average 2.8 that means approximately "medium". Scientific capacity of the department from students' point of view for newly established universities is 2.4 that mean "below average" and the students give 2.4 for transportation and city that are the small cities and its mean "below average".

\section{Conclusion}

According to the results from the questionnaires; an important part of the observed problems in civil engineering education is coming from national problems in higher education. Approaches of government to the problems in higher education are very important for a permanent solution but this approach is to be consensus with universities. Two main judgments can be presented about the civil engineering departments in Turkey. Firstly, civil engineering education performed without appropriate infrastructure, buildings and equipments except for a small 
number of qualified developed universities. Secondly, as a result of the first judgment, unemployment of the inadequate civil engineers is the other major problem. Expenditures from university budget for education of redundant civil engineers may be used for educating more qualified engineers.

In recent years, it can be observed that engineering teaching and education spreads across the country but the quality decreases. Customers recognize that quality is an important attribute in products and services such as in engineering education quality can be defined with same arguments. All activities related to teaching should be directed to the satisfaction of students but limited facilities should be used effectively and efficiently. Highest productivity for the lowest cost is the main purpose for regeneration process of education in all countries. Education is a long, difficult and expensive process so a productive and sustainable education should be planned using the evaluation of civil engineering education in Turkey from the students' point of view.

\section{References}

Albayrak, G., Value Engineering Applications on Civil Engineering Education in Turkey, in Turkish, Master of Science Thesis, 2012.

Albayrak, G., Özdemir, İ., Albayrak, U., A Statistical Evaluation of Civil Engineering Education in Turkey in terms of Value Engineering Concepts, Turkish Journal of Engineering, Science and Technology, Volume 2, Issue 2, 2014, p. 76-82.

Albayrak, G., Özdemir, I., Albayrak, U., An Evaluation of Civil Engineering Education in Turkey from the Students' Point of View, International Scientific Conference People Buildings and Environment, PBE2012, Lednice, Czech Republic, 7-9 November 2012, p. $778-786$.

Kahraman, S., Ertutar, Y. ve Gi'rgi, S.C., Engineering education and accreditation, 1st Civil Engineering Education Symposium Proceedings, 2009, Antalya, s. 277-284.

Toklu, Y.C., New trends in civil engineering education, 1st Civil Engineering Education Symposium Proceedings, 2009, Antalya, 155-166.

Müdek, Müdek training workshop, 2012, URL: http://www.mudek.org.tr/tr/ calistay/201204/20120414-MUDEK_ Degerlendirme_Olcutleri.pdf

Asce, The vision for civil engineering in 2025 , The Summit on Future of Civil Engineering, June 21-22, 2006, Reston, VA, USA.
Saka, Y. ve Yaman, S., University ranking systems; criteria and criticisms, Yüksek Öğretim ve Bilim Dergisi, 2011, Cilt:1, Sayı:2, s. 72-79.

Birin, F. ve Koç, V., New approaches to the general structure of civil engineering education and development in Turkey, 1st Civil Engineering Education Symposium Proceedings, 2009, Antalya, s. 343-352.

Uçkun, S., Department of electrical and electronic engineering in Gaziantep University and engineering education in our country in the 2000's, IV. Electromechanical Symposium Proceedings, 1997, Bursa, s. 170-173.

Kilanç, B., Higher Education Programs in civil engineering, 2007, URL: http://www. dogrutercih.com/dosyalar/ozel-dosya-12. pdf.

Felder, R. M., Brent, R. and Prince, M. J., Engineering instructional development: programs, best practices and recommendations, Journal of Engineering Education, 2011, Cilt 100, No. 1, s. 89-122.

Ersoy, U., Problems, causes and solutions in civil engineering education, 11st Civil Engineering Education Symposium Proceedings, 2009, Antalya, s. 23-29. 


\section{APPENDIX}

Survey for civil engineering students

\begin{tabular}{l|l|l|l|l|}
1 & 2 & 3 & 4 & 5
\end{tabular}

1) How much did you prefer your department?

2) How is your department's level in your university in terms of an effective department?

3) Is it a rightfulness decision that you chose this department?

4) Is your programs curriculum actual and adequate?

5) How do you evaluate your department's scientific sufficiency compare with other civil engineering departments?

6) What is your department's level in your faculty in terms of priority compare with other departments?

7) Are there a lot of departments in your faculty?

8) Is your department's total number of academician sufficient?

9) Does attach importance practising in the lessons and laboratories?

10) Are there sufficient lessons that include theoretical and scientific methods?

11) How much do you understand the topics that taught you?

12) Does attach importance professional and institutional training?

13) Are the materials adequate like books, internet, and computer laboratories etc.?

14) Is your city support your department?

15) How is your city in terms of transportation and accommodation?

16) Is it sufficient that your departments total number of publication (journal, article, project, research) in a year?

17) How is your academicians' participation in changing programs for education and research?

18) How is your department's participation level in evaluation and accreditation foundations like MUDEK, ADEK and ABET etc.?

19) How is your employment opportunity after graduate?

20) Are there a lot of deficiencies in your department?

(Not write name, surname or comment. Only grade your opinion.)

Evaluation criteria:
(5): Excellent
(4): Above average
(3): Average
(2): Below average
(1): Very poor 